\title{
Medical scientific output and specialization in Latin American countries
}

\author{
Grisel Zacca-González ${ }^{1}$ Zaida Chinchilla-Rodríguez ${ }^{2,4}$ • \\ Benjamín Vargas-Quesada ${ }^{3,4}$
}

Received: 28 February 2017

(C) Akadémiai Kiadó, Budapest, Hungary 2018

\begin{abstract}
Smart specialization" allows one to identify national strengths and weaknesses within research fields and establish priorities accordingly. It may be a useful strategy for building scientific capacity in developing and peripheral countries. The objective of this paper is to characterize the scientific output and specialization of the most productive Latin American countries with focus on international collaboration and impact. We conducted a descriptive study based on the SCImago Institutions Ranking (SIR) portal, in the field of Medicine, for the period 2003-2013. The set of indicators applied was based on documents, citation, and collaboration. The results show that at the global level, Surgery, Cardiology, Oncology, Neurology, and Public Health are the most productive subjects in Medicine; in Latin America the most productive topics are Public Health, Infectious Diseases, Surgery, Neurology, and Cardiology and Cardiovascular Medicine. The most prolific countries are Brazil, Mexico and Argentina, though the ones having greater impact and more collaboration are Peru, Puerto Rico, and Argentina. The most productive and visible fields, such as Oncology, Cardiology, and Infectious Diseases, are related to major global health problems involving chronic and emerging diseases. This information could be useful to design pragmatic policies, to encourage research in key fields in order to respond better to the health needs of a given population.
\end{abstract}

Keywords Medicine · Bibliometrics - Subject categories · Latin America · Activity Index $\cdot$ Scientific output

Grisel Zacca-González

grisel.zacca@infomed.sld.cu

1 Department of Teaching and Research, National Medical Sciences Information Centre-Infomed, Calle 23 No. 654 entre D y E, Vedado, 10400 Havana, Cuba

2 CSIC, Institute of Public Goods and Policies (IPP), Albasanz 26-28, 28037 Madrid, Spain

3 Department of Information and Communication, University of Granada, Campus de Cartuja s/n, 18071 Granada, Spain

$4 \quad$ SCImago Research Group, Granada, Spain 


\title{
Mathematical Subject Classification 94
}

\author{
JEL Classification D8
}

\section{Introduction}

The Report on World Health, with its focus on research directed toward universal health coverage, emphasizes the need to systematically evaluate the strengths and weaknesses of research efforts for the benefit of health, country by country, in the entire world. It insists that when public funding is spent on research, there should be mechanisms facilitating debate about prioritites, to develop research capacities, establish norms, and translate the results into policies and practices (World Health Organization [WHO] 2013). Scientific capacity refers to the infrastructure, investment, institutional and regulatory framework, plus personnel available to conduct scientific research and technological development; it derives from historical patterns and political and economic priorities (Wagner et al. 2001). In this sense, there is increasing recognition of the need for greater efforts aimed specifically at building the capacity of developing countries to generate, disseminate and use S\&T to address both current and future needs in national, regional and international arenas (Parliamentary Office of Science and Technology 2004).

"Smart specialization" may be a useful strategy for capacity building. It is the term used to designate a vertically-oriented policy framework that reflects priorities set at the regional level. It combines bottom-up and top-down processes for setting priorities when it comes to public investment in knowledge. This strategy helps ensure that governmental efforts and resources are not spread out over all activities to the same extent. Hence, a key issue is how to select the most relevant areas for governments to invest their resources (Organisation for Economic Co-operation and Development [OECD] 2013). Such diagnosis foments positive transformation, either by updating areas that lag behind, advancing along new lines of interest, or fortifying some of the areas that prove competitive at international level and have demonstrated their impact on public health. Bearing in mind this overall strategy, it is relevant to identify the particular strengths and weaknesses of research endeavors in areas with high social and economic impact such as Medicine (Medical and Health Sciences), so as to establish common objectives that facilitate the development of regional strategies and the assignment of public funds to the major health problems. This provides complementary information of great value for decision-making, favoring $\mathrm{R}+\mathrm{D}$ activities in research areas that are most pressing for health priorities. Pertinent research is essential for the design and implementation of tools for health interventions, policies and services (Manterola Delgado 2014).

Given its relevance and the volume of scientific production, Medicine has been the object of research in numerous bibliometric studies (European Commission 2013), whether national, regional or transnational (OECD 2013). The results generated by the study of scientific output with international visibility have proven useful to promote regional or national capacity to carry out health research and further international collaboration (Masic 2013). In studying the specialization of one aggregate, the Activity Index has frequently been used; some examples can be found in national or international studies that describe current research and research potential (Chinchilla-Rodríguez et al. 2016a; Glänzel 2000; Glänzel et al. 2006; OECD 2013; Zacca-González et al. 2014a), book production (TorresSalinas et al. 2013) and scientific output by universities (Codina-Canet et al. 2013; Souza et al. 2015). 
In order to provide a diagnostic tool for identifying strengths and weaknessess in the research endeavors of medical and health science in Latin America, the main objective of this article is to characterize scientific output and specialization of the most productive Latin American countries with focus on international collaboration and impact.

\section{Materials and methods}

The data were retrieved from the portal SCImago Institutions Rankings (2017) based on Scopus data for the period 2003-2013. Scopus, the largest database of peer-reviewed literature, contains over 21,500 titles from more than 5000 international publishers. It provides the most complete view of world scientific output in the fields of technology, medicine, science, social sciences, and the arts and humanities. Medical and Health Sciences represent $32 \%$ of its total content, with 12,912 titles (source types: $90.5 \%$ journal articles, $2.9 \%$ conference papers and $0.3 \%$ books) (Elsevier 2016).

The thematic classification of Scopus (ASJC) in the area of Medicine is taken into account to characterize the research fields in Medicine. At the global level, we worked with the 48 subject categories of the area of Medicine, and a worldwide aggregate. At the national level, 10 Latin American countries with the greatest output were selected, the latter representing $99.7 \%$ of total regional output in the field of Medicine. The bibiliometric indicators used were:

- Output: Total number of documents published by a country or region in the thematic area of Medicine.

- Growth rate (\% GR): Percentage-wise difference in the number of papers published with respect to the previous period.

- Normalized Citation Impact (NCI): Relative number of citations received by each thematic category, compared with the world average of citations received by a paper of the same document type, year and category. The normalization of the citation value is done at individual article level. The values show the relationship between the mean scientific impact of a country and the worldwide average as a whole, with a score of 1 . Therefore, an NI of 0.8 means that the country is cited $20 \%$ less than the world average; a score of 1.3 means it is cited $30 \%$ more than the world average.

- \% International Collaboration (\% IC): Percentage of documents involving authors from more than one country.

- $\%$ Output in Q1 (\% Q1): Percentage of publications in journals included in the first quartile (top 25\%) in their category as graded by SCImago Journal Rank (SJR) indicator.

- Leadership (\% Lead): Percentage of documents published by a country in which the "Corresponding author" is affiliated with a national institution.

- Excellence (Exc): Percentage of documents included within the set of the $10 \%$ most cited papers in that category. The percentages can be compared with the "world expected" value established for the top $10 \%$.

- Excellence with leadership (\% EwL): Percentage of documents of excellence considered as the main contributor.

- Relative Specialization Index (RSI) or Relative Activity Index: this measure indicates whether a country has a relatively higher or lower share in world publication in a field than its overall share in world total publication. It is calculated based on the Thematic Specialization Index (TSI), an indicator closely related to the so-called Activity Index 
(AI) long used in bibliometrics, which, in turn is a version of the economists' Comparative Advantage Index (Glänzel 2000; Zacca-González et al. 2014a).

$$
\mathrm{TSI}=\frac{\text { Output category }(\text { country }) / \text { total output }(\text { country })}{\text { Output category }(\text { World }) / \text { total output }(\text { World })}
$$

$\mathrm{RSI}=\frac{\mathrm{TSI}-1}{\mathrm{TSI}+1}$; RSI can take values in the range -1 to 1 , with 0 corresponding to the world average, hence RSI $<0$ indicates a lower than average output rate, and RSI $>0$ would be higher than average activity.

\section{Results and discussion}

\section{Distribution of subject areas at the global and regional level}

In the period 2003-2013, a total of 5,953,458 documents were published worldwide in the area of Medicine, representing $28.13 \%$ of total documents registered in the Scopus database for that period. Their evolution (Fig. 1) shows a rising trend, with an average annual growth rate of $5.45 \%$ and total growth over the period amounting to $69.63 \%$. The increase was less accelerated than the one seen for global output, including all areas, which was 100. $25 \%$.

The subject distribution (Table 1) indicates that, of the total output in Medicine, the most productive subject categories are: Surgery, Cardiology and Cardiovascular Medicine, Oncology, Neurology, and the domain of Public Health, Occupational and Environmental Health. As for growth, all showed a positive trend, but most notably in the case of Complementary and Alternative Medicine, growing 227.94\% in the eleven-year period, followed by the categories Health Informatics (173.63\%), Health Policy (157.74\%) and Emergency Medicine (142.53\%). Those showing slow growth were Drug Guides $(1.43 \%)$, Transplantation (15.93\%), Reproductive Medicine (32.52\%), Rehabilitation (33.90\%), Physiology (34.05\%) and Nephrology (35.52\%). Altogether, 12.62\% of the publications were produced in international collaboration.

In Latin America the most productive subject areas were: Public Health, Environmental and Occupational Health (9.20\%), Infectious Diseases (8.78\%), Surgery (7.11 outstanding Neurology (clinical) (5.67\%), Cardiology and Cardiovascular Medicine (5.11\%), Microbiology (4.41\%), Pediatrics, Perinatology and Child Health (3.90\%), Psychiatry and

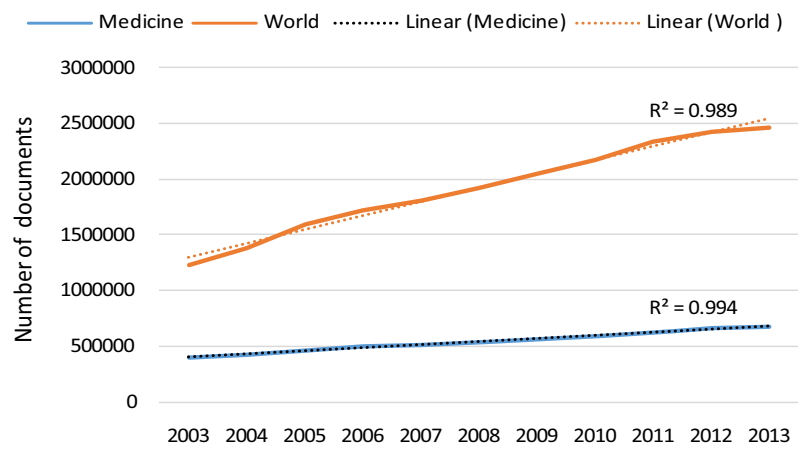

Fig. 1 Evolution in the number of documents in the area of Medicine. Scopus 2003-2013 
Table 1 Subject areas of world scientific output in Medicine: output, international collaboration. Source: SCImago Institutions Rankings, based on Scopus data, elaborated by the authors

\begin{tabular}{|c|c|c|c|c|c|c|c|c|}
\hline \multirow[t]{2}{*}{ Subject category } & \multicolumn{4}{|l|}{ World } & \multicolumn{4}{|c|}{ Latin America } \\
\hline & Output & $\begin{array}{l}\% \\
\text { Doc. }\end{array}$ & $\begin{array}{l}\text { GR } \\
(\%)\end{array}$ & $\% \mathrm{IC}$ & Output & $\begin{array}{l}\% \\
\text { Doc. }\end{array}$ & GR $(\%)$ & $\%$ IC \\
\hline Surgery & 459,735 & 7.72 & 64.95 & 6.66 & 18,135 & 7.11 & 219.89 & 14.99 \\
\hline $\begin{array}{l}\text { Cardiology and Cardiovascular } \\
\text { Medicine }\end{array}$ & 377,570 & 6.34 & 63.77 & 11.99 & 13,036 & 5.11 & 157.03 & 20.99 \\
\hline Oncology & 359,713 & 6.04 & 90.71 & 14.17 & 6161 & 2.42 & 189.04 & 40.48 \\
\hline Neurology (clinical) & 344,276 & 5.78 & 70.42 & 13.89 & 1,4469 & 5.67 & 79.40 & 23.11 \\
\hline $\begin{array}{l}\text { Public Health, Environmental } \\
\text { and Occupational Health }\end{array}$ & 316,149 & 5.31 & 121.58 & 14.3 & 2,3455 & 9.20 & 261.92 & 24.6 \\
\hline $\begin{array}{l}\text { Radiology, Nuclear Medicine } \\
\text { and Imaging }\end{array}$ & 291,467 & 4.90 & 68.24 & 12.01 & 6550 & 2.57 & 194.63 & 27.8 \\
\hline Psychiatry and Mental Health & 282,079 & 4.74 & 80.34 & 13.33 & 9740 & 3.82 & 201.11 & 29.94 \\
\hline Infectious Diseases & 260,809 & 4.38 & 69.30 & 22 & 2,2385 & 8.78 & 116.59 & 37.73 \\
\hline $\begin{array}{l}\text { Pediatrics, Perinatology and } \\
\text { Child Health }\end{array}$ & 248,710 & 4.18 & 59.32 & 9.23 & 9956 & 3.90 & 152.24 & 21.51 \\
\hline Pharmacology (medical) & 209,712 & 3.52 & 76.14 & 12.77 & 4487 & 1.76 & 168.67 & 43.37 \\
\hline $\begin{array}{l}\text { Orthopedics and Sports } \\
\text { Medicine }\end{array}$ & 192,370 & 3.23 & 94.43 & 10.64 & 5974 & 2.34 & 530.00 & 21.28 \\
\hline Immunology and Allergy & 176,439 & 2.96 & 56.75 & 18.27 & 7221 & 2.83 & 121.53 & 37.31 \\
\hline $\begin{array}{l}\text { Endocrinology, Diabetes and } \\
\text { Metabolism }\end{array}$ & 175,883 & 2.95 & 78.37 & 15.95 & 8236 & 3.23 & 168.54 & 25.41 \\
\hline Obstetrics and Gynecology & 170,682 & 2.87 & 49.64 & 10.01 & 9229 & 3.62 & 222.09 & 20.48 \\
\hline Gastroenterology & 162,504 & 2.73 & 52.98 & 8.26 & 5197 & 2.04 & 69.84 & 14.62 \\
\hline Hematology & 154,873 & 2.60 & 44.52 & 14.22 & 4643 & 1.82 & 125.64 & 27.44 \\
\hline $\begin{array}{l}\text { Pulmonary and Respiratory } \\
\text { Medicine }\end{array}$ & 148,697 & 2.50 & 59.62 & 10.97 & 4920 & 1.93 & 157.28 & 28.84 \\
\hline $\begin{array}{l}\text { Pathology and Forensic } \\
\text { Medicine }\end{array}$ & 140,393 & 2.36 & 52.10 & 12.89 & 4847 & 1.90 & 155.33 & 31.79 \\
\hline Dermatology & 131,433 & 2.21 & 51.77 & 9.08 & 6785 & 2.66 & 179.12 & 17.91 \\
\hline Ophthalmology & 131,381 & 2.21 & 46.95 & 11.26 & 5398 & 2.12 & 122.92 & 24.9 \\
\hline Physiology (medical) & 124,006 & 2.08 & 34.05 & 17.63 & 4345 & 1.70 & 57.78 & 34.08 \\
\hline Internal Medicine & 122,065 & 2.05 & 60.78 & 12.11 & 3389 & 1.33 & 86.49 & 26.85 \\
\hline Microbiology (medical) & 116,542 & 1.96 & 47.65 & 16.16 & 11,238 & 4.41 & 60.57 & 30.24 \\
\hline $\begin{array}{l}\text { Anesthesiology and Pain } \\
\text { Medicine }\end{array}$ & 112,495 & 1.89 & 36.70 & 9.45 & 3549 & 1.39 & 118.62 & 15.55 \\
\hline Urology & 107,475 & 1.81 & 61.40 & 9.32 & 3577 & 1.40 & 81.35 & 20.57 \\
\hline Otorhinolaryngology & 104,262 & 1.75 & 73.55 & 7.76 & 6745 & 2.65 & 207.45 & 14.42 \\
\hline Health Policy & 99,415 & 1.67 & 157.74 & 9.39 & 5115 & 2.01 & 579.44 & 14.6 \\
\hline $\begin{array}{l}\text { Critical Care and Intensive } \\
\text { Care Medicine }\end{array}$ & 89,750 & 1.51 & 50.13 & 10.02 & 2570 & 1.01 & 286.27 & 31.91 \\
\hline Genetics (clinical) & 86,515 & 1.45 & 63.95 & 27.92 & 3245 & 1.27 & 76.42 & 50.02 \\
\hline Epidemiology & 82,039 & 1.38 & 131.14 & 19 & 3576 & 1.40 & 147.37 & 43.32 \\
\hline Rehabilitation & 77,783 & 1.31 & 33.90 & 8.52 & 2454 & 0.96 & 631.91 & 17.32 \\
\hline Health Informatics & 68,853 & 1.16 & 173.63 & 12.07 & 2226 & 0.87 & 150.89 & 28.17 \\
\hline Geriatrics and Gerontology & 67,762 & 1.14 & 90.51 & 12.32 & 1654 & 0.65 & 724.24 & 31.38 \\
\hline
\end{tabular}


Table 1 continued

\begin{tabular}{|c|c|c|c|c|c|c|c|c|}
\hline \multirow[t]{2}{*}{ Subject category } & \multicolumn{4}{|l|}{ World } & \multicolumn{4}{|c|}{ Latin America } \\
\hline & Output & $\begin{array}{l}\% \\
\text { Doc. }\end{array}$ & $\begin{array}{l}\mathrm{GR} \\
(\%)\end{array}$ & $\% \mathrm{IC}$ & Output & $\begin{array}{l}\% \\
\text { Doc. }\end{array}$ & GR $(\%)$ & $\% \mathrm{IC}$ \\
\hline Nephrology & 65,556 & 1.10 & 35.52 & 12.06 & 2051 & 0.80 & 66.94 & 27.21 \\
\hline Rheumatology & 65,090 & 1.09 & 66.04 & 15.02 & 3302 & 1.29 & 128.75 & 25.14 \\
\hline Emergency Medicine & 64,078 & 1.08 & 142.53 & 5.63 & 622 & 0.24 & 262.07 & 35.85 \\
\hline Reproductive Medicine & 62,914 & 1.06 & 32.52 & 13.46 & 3071 & 1.20 & 107.47 & 32.72 \\
\hline Transplantation & 62,461 & 1.05 & 15.93 & 12.09 & 2328 & 0.91 & 93.75 & 22.81 \\
\hline $\begin{array}{l}\text { Complementary and } \\
\text { Alternative Medicine }\end{array}$ & 61,862 & 1.04 & 227.94 & 11.29 & 3635 & 1.43 & 273.97 & 21.38 \\
\hline Hepatology & 59,809 & 1.00 & 70.32 & 11.45 & 1421 & 0.56 & 146.58 & 26.11 \\
\hline Biochemistry (medical) & 50,665 & 0.85 & 55.82 & 14.55 & 1813 & 0.71 & 185.00 & 28.3 \\
\hline Histology & 48,215 & 0.81 & 58.85 & 15.32 & 2393 & 0.94 & 190.00 & 29.13 \\
\hline Anatomy & 32,534 & 0.55 & 58.74 & 18.34 & 3030 & 1.19 & 317.53 & 30.59 \\
\hline Family Practice & 30,528 & 0.51 & 41.75 & 4.95 & 265 & 0.10 & 200.00 & 29.81 \\
\hline Embryology & 13,406 & 0.23 & 37.97 & 16.37 & 486 & 0.19 & 41.03 & 45.06 \\
\hline Drug Guides & 1085 & 0.02 & 1.43 & 10.51 & 15 & 0.01 & -100.00 & 46.67 \\
\hline $\begin{array}{l}\text { Reviews and References } \\
\text { (medical) }\end{array}$ & 104 & 0.00 & $*$ & 4.81 & 2 & 0.00 & 0.00 & 0 \\
\hline Total & $5,953,458$ & 100 & 69.63 & 12.62 & 255,002 & 100 & 147.43 & 24.74 \\
\hline
\end{tabular}

$\%$ Doc. World or regional documents share, GR (\%) growth rate, \% IC International Collaboration

*This subject category began in 2005

Mental Health (3.82\%) and Obstetrics and Gynecology (3.62\%). The region is highly specialized in Microbiology, Infectious Diseases, and Public Health, Environmental and Occupational Health. One of the most prolific research fields, Oncology was the subject with the highest percentage of publications in international collaboration.

\section{Medical subject areas in Latin American countries}

Table 2 shows some basic results of the most prolific Latin American countries in the research field of Medicine, which overall contribute $99.7 \%$ of the regional total, the greatest producers being Brazil, Mexico and Argentina, with almost $80 \%$ of the total. Brazil is the country producing the most-over $50 \%$ of regional output-followed by Mexico, with almost $15 \%$. However, the countries that witnessed the greatest increase in their volume of output during the decade 2003-2013 were Colombia and Peru. Still, given the high volume of Brazil's output, in conjunction with its prominent leadership, we must underline its growth as very relevant. The same consideration could be extended to the leadership shown by Mexico and Argentina.

Interesting observations can be made with respect to the dimensions of quality and output. Firstly, only Peru, Puerto Rico and Argentina manage to surpass the world average for impact (NCI). These same countries are also the ones publishing more in journals of high quality (percentage of papers in Q1). Indeed, Peru and Puerto Rico published over half of their documents in journals of the first quartile, and show a high volume of output of 
Table 2 Bibliometric indicators of the most prolific Latin American countries in Medicine

\begin{tabular}{lrrlllllll}
\hline Country & Output & GR $(\%)$ & \% LAC & NCI & \% Q1 & \% Exc & \% Lead & \% EwL & \% IC \\
\hline Brazil & 137,562 & 186.10 & 53.95 & 0.8 & 36.14 & 6.89 & 87.26 & 4.10 & 21.75 \\
Mexico & 36,628 & 97.47 & 14.36 & 0.78 & 33.25 & 7.17 & 78.29 & 2.80 & 30.02 \\
Argentina & 26,436 & 95.72 & 10.37 & 1.09 & 42.14 & 9.53 & 76.33 & 3.56 & 38.04 \\
Chile & 16,326 & 168.77 & 6.40 & 0.89 & 35.7 & 8.96 & 68.53 & 3.50 & 37.09 \\
Colombia & 11,564 & 412.47 & 4.53 & 0.81 & 30.2 & 7.71 & 70.01 & 1.76 & 43.08 \\
Cuba & 9265 & 96.49 & 3.63 & 0.27 & 12.4 & 2.48 & 76.38 & 0.71 & 20.51 \\
Venezuela & 6050 & 45.22 & 2.37 & 0.67 & 27.04 & 6.13 & 74.16 & 1.74 & 37.64 \\
Peru & 4321 & 229.84 & 1.69 & 1.41 & 50.13 & 12.96 & 46.39 & 2.24 & 67.51 \\
Puerto Rico & 3344 & 32.64 & 1.31 & 1.38 & 54.01 & 14.62 & 58.05 & 3.14 & 59.84 \\
Jamaica & 2761 & 81.41 & 1.08 & 0.78 & 31.84 & 5.54 & 72.91 & 1.38 & 63.75 \\
Latin America & 255,002 & 147.43 & 100 & 0.78 & - & 6.70 & 84.71 & 3.39 & 24.74 \\
\hline
\end{tabular}

GR $(\%)$ growth rate, \% LAC regional documents share, $N C I$ normalized citation impact, \% Q1 \% output in Q1, \% Exc excellence, \% Lead leadership, \% EwL excellence with leadership, \% IC international collaboration

excellence, associated with low leadership, and low excellence with leadership in comparison with the rest of the countries, yet with high international collaboration. The opposite is true of Cuba: only $12.4 \%$ of its output appears in journals of high impact, its output of excellence is scanty, and it shows the lowest levels of collaboration. Argentina and Chile are the countries of high output (volume) found to publish more output of excellence. Interestingly enough, none of these countries was capable of achieving good results in output when they themselves led the research endeavor-not even Brazil, with $4 \%$ of excellence in leadership.

\section{Subject distribution of the scientific output of Latin American countries in Medicine}

Figure 2 shows a combination of the indicators: specialization, impact, and volume of scientific publications (left), and the percentage of publications in international collaboration and the yield measured in terms of percentage of output in Q1 (right). Peru, Puerto Rico and Jamaica have high levels of international collaboration in all the most productive categories. Puerto Rico publishes over half of its output in journals pertaining to the top quartile in all categories, Obstetrics and Gynecology being the one with the highest production in the most prestigious journals in this area.

In Public Health, Environmental and Occupational Health, the sole country with specialization below the world average is Argentina. Those with most meritorious effort are Peru, Cuba and Jamaica. In terms of impact, Peru, Puerto Rico and Argentina are comfortably above the world average. Greater international collaboration is seen for Peru, Puerto Rico and Jamaica, the former two having a greater \% in Q1. Brazil and Cuba are the countries with the lowest levels of international collaboration, and the latter is moreover the country with the fewest publications in top journals. The countries of Latin America publish less overall, in Q1 journals in the domain of Public Health, Environmental and Occupational Health than in the other categories. When it comes to Infectious Diseases, Peru is by far the most specialized country in the region, and this is clearly its most 
Fig. 2 (On the left) Relative Specialization Index (RSI), Normalized Citation Impact (NCI) and volume of publications (size of sphere) of the 10 most prolific categories in the area of Medicine within the Latin American region. (On the right) Percentage of International Collaboration and percentage of publications in journals of the first Quartile (\% Output in Q1)

productive category. Peru and Puerto Rico achieve high impact and publish over $50 \%$ of their output in Q1 journals. Peru, together with Jamaica, shows a high percentage of publications involving international collaboration.

In several of the countries studied, Surgery proves a weak spot. As a specialized area it is strong only in Cuba and Jamaica, yet it reaches high impact (above world average) only in Puerto Rico, with 55\% more citations than the world average in normalized citation, and to a much lesser extent in Argentina, with 13\%. Generally, there are lower rates of international collaboration in this area and fewer documents are published in the journals of the first quartile as compared with the other high productivity categories. Though the indicators of internationalization and yield of research are frankly low in Cuba, it is also true that no Latin American country obtains high values in both of these indicators. Jamaica has the highest collaboration, whereas Puerto Rico has more output in journals of the top quartile.

In Neurology (clinical), almost all the countries are found in the quadrant indicative of minor effort and impact, when compared internationally. Only Cuba and Brazil are found above the value of reference in specialization. In impact, a high value is assigned to Puerto Rico, followed at some distance — but still above the average-by Argentina. Within this domain, less is published in journals of the first quartile. Brazil and Mexico are involved in less international collaboration and publish much less in high impact journals. Jamaica, Peru and Puerto Rico are the countries with the most internationalized output; furthermore, Jamaica and Puerto Rico publish the most in Q1 journals.

The subject Cardiology and Cardiovascular Medicine constitutes a weak spot in nearly all the countries of Latin America, regarding both activity and impact. It attains high impact in Chile alone, at $42 \%$ above the world average, publishing over $65 \%$ of its output in the top journals. Puerto Rico also shows high figures for this indicator. International collaboration is particularly low in Brazil and Mexico. The \% in Q1 is very low in Cuba, and low in Colombia and Mexico.

Microbiology (medical), on the other hand, can be viewed as a strong subject in the countries of the region, with the exception of Chile. In impact, Colombia, Peru and Puerto Rico are above the world average. This domain sees a good proportion of publication in high impact journals. There is a combination of limited internationalization and scarce publication in high impact journals for Brazil and Argentina, which contrasts with the values reached by the other countries. The best results for these two indicators are found for Peru and Jamaica.

In Psychiatry and Mental Health, most Latin American countries show low specialization-the exceptions in this case being Cuba and Puerto Rico. Fairly high impact is achieved by Jamaica, Puerto Rico and Colombia. Cuba has low internationalization. In contrast, Peru and Puerto Rico show the best results for these two parameters.

In Pediatrics, Perinatology and Child Health, Brazil, Mexico and Venezuela appear in the quadrant that reflects weakness in terms of activity and impact. Showing high impact are Peru, Colombia and Puerto Rico, whereas the greatest specialization is exhibited by Cuba and Chile. This is one of the domains characterized by a markedly high degree of international collaboration in Latin America. Again we find Peru and Puerto Rico with high international collaboration and publications in Q1, and again Cuba shows the lowest 
Public Health, Environmental and Occupational Health
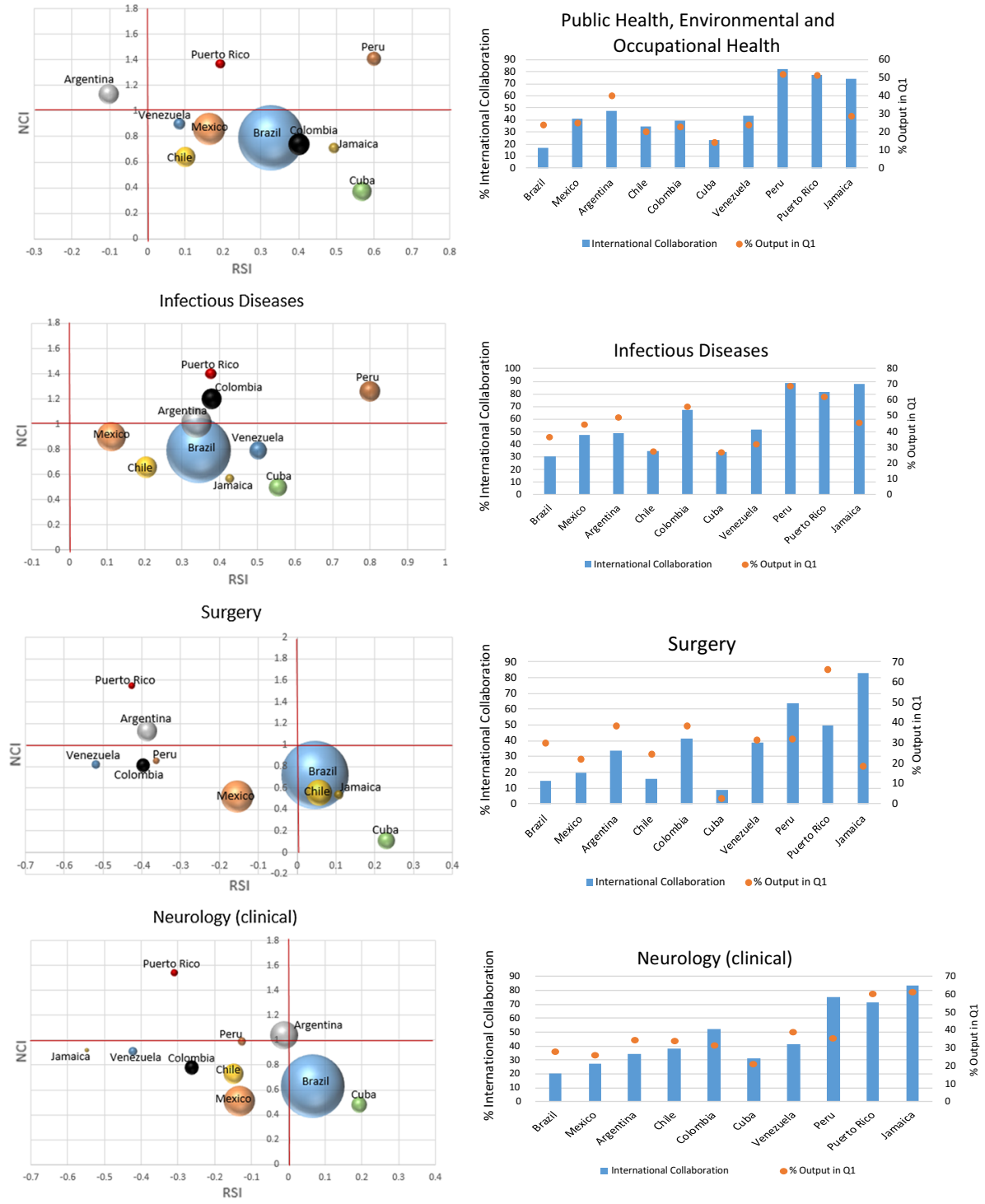

Cardiology and Cardiovascular Medicine
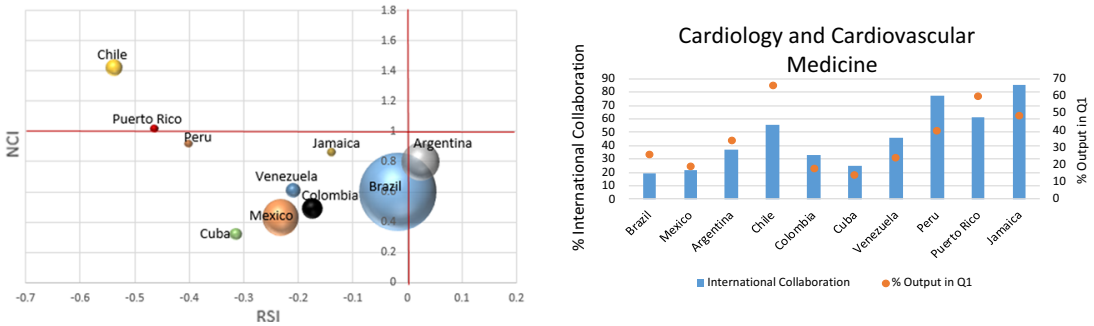


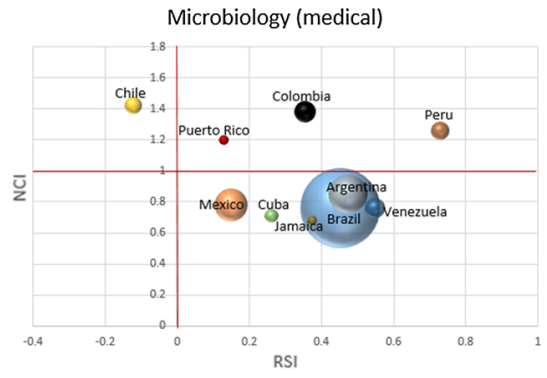

Psychiatry and Mental Health

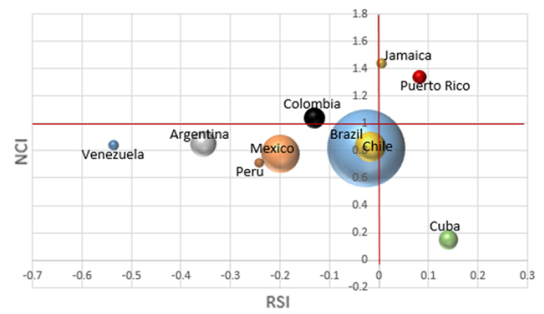

Pediatrics, Perinatology and Child Health

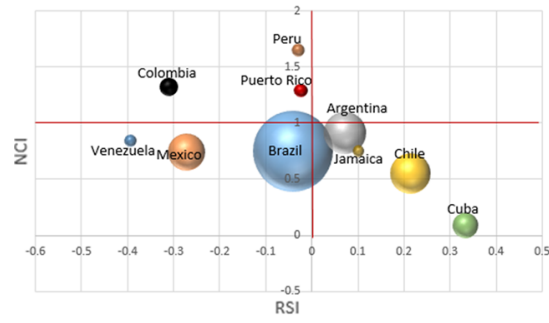

Obstetrics and Gynecology

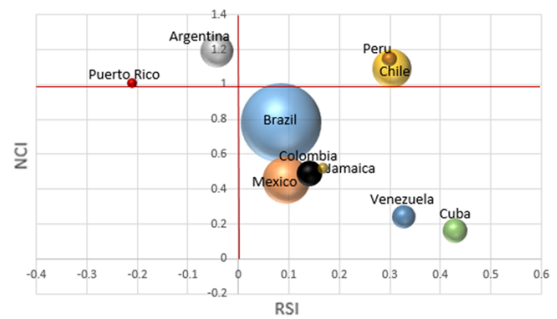

Endocrinology, Diabetes and Metabolism

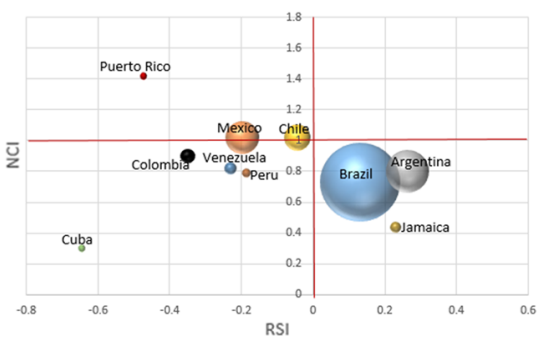

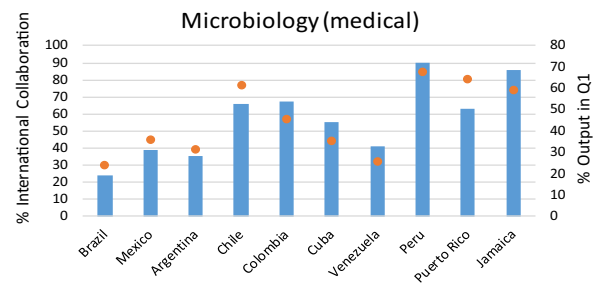

In International Collaboration \% Output in Q1
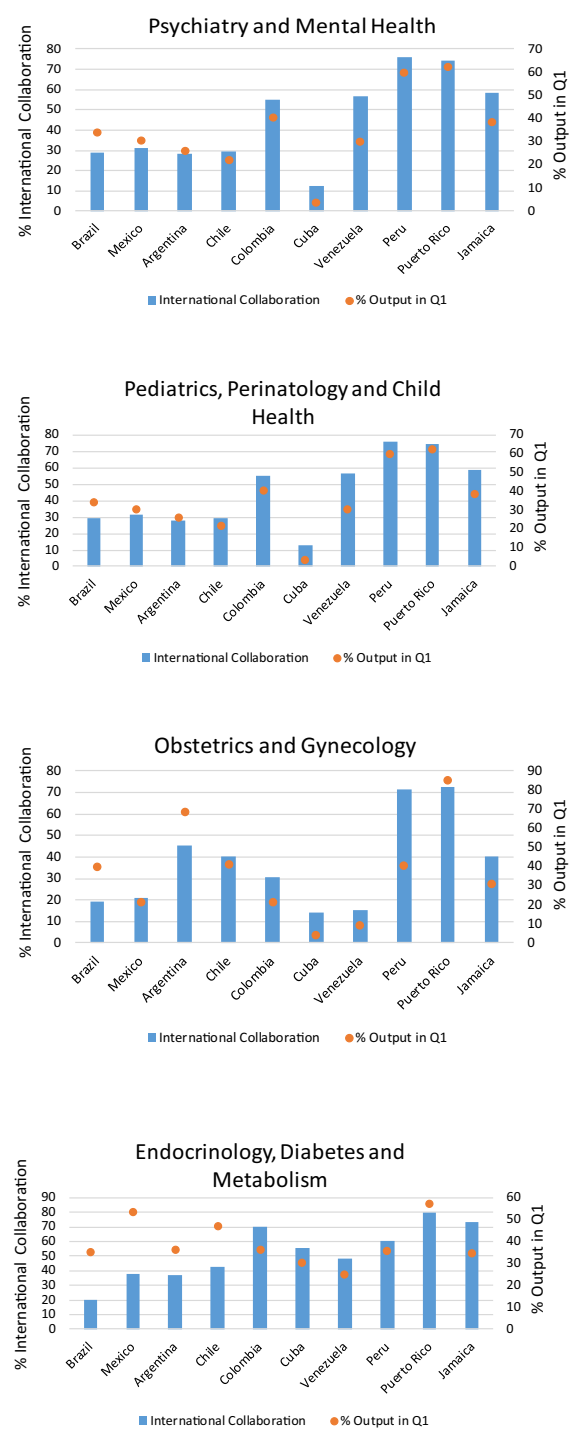

Fig. 2 continued 
values. Curiously, the four most productive countries are found to have the poorest results for these two indicators.

Related with the previous medical domain is Obstetrics and Gynecology. In this case, however, most countries have a degree of specialization that lies well above the world standard. In impact Peru and Chile stand out among the most specialized producers, along with Argentina, despite its low level of specialization. Cuba is likewise highly specialized in this domain. Obstetrics and Gynecology is characterized by a low level of collaboration between Latin America and other countries. Cuba and Venezuela show poor results in output, collaboration, and \% of output in Q1.

Finally, in the medical category of Endocrinology, Diabetes and Metabolism we find no country in the strong quadrant in terms of specialization and impact; yet in this field the Latin American countries actually publish a high proportion of studies in high impact journals. Activity is the greatest in Brazil, Argentina and Jamaica. The impact is low in general, except that of Puerto Rico, whose output is scarce and hardly specialized, but involves a high degree of internationalization and appears in journals of the first quartile $(80 \%)$. The most productive countries in this domain are found to have the lowest degree of international collaboration.

\section{Discussion and conclusions}

This paper presents a preliminary analysis of the worldwide distribution of subject areas in medical research - that is, published research-derived from bibliometric indicators. Bibliometrics is a particularly useful instrument in the field of Medicine, as it is a field entailing high costs, high socioeconomic impact, and a strong foundation of international peer-reviewed journals for scientific communication (van Raan 2014). Although smart specialization should ideally be identified in a multidimensional and sophisticated way (Forray and Goenega 2013), scientific activity measured through publications in combination with the percentages of international collaboration and research performance, constitutes an essential complement. In this sense, we provide findings that reflect the main strengths and weaknesses in the scientific activities of Latin American countries, making the results useful for improving a country's strategies and efforts within the global scientific system.

Ischaemic heart disease and cerebrovascular accidents have loomed prominently as the main causes of death worldwide during the past 15 years (WHO 2017). Chronic Pulmonary Obstructive disease, lung cancer, diabetes mellitus, diarrheic diseases and tuberculosis are also largely responsible for world morbidity and mortality. The WHO's distribution of the global burden of diseases coincides with the one that comes to light through our analysis of the most productive areas on the global scale: Cardiology and Cardiovascular Medicine, Oncology, Neurology (clinical), Public Health, Environmental and Occupational Health, Psychiatry and Mental Health, Infectious Diseases, and Endocrinology, Diabetes and Metabolism. Due to the fact that Surgery is a necessary-hence common-procedure in several specialities, its research field is the most productive worldwide. At the other extreme, among the least productive categories, we find Family Practice, a domain that calls for support at all levels, given its essential importance for any health system. In the case of Drug Guides (the least productive area), there is no corresponding specialized field, and it is a specific type of document, which explains its scanty output and low growth. 
Even though all subject areas showed positive evolution, the most remarkable growth was undergone by Complementary and Alternative Medicine, a finding that matches the results of a study carried out using the Science Citation Index Expanded database (Fu et al. 2011). Also noteworthy is the evolution of Health Informatics, a new research area whose rapid growth has likewise been documented previously (Liang 2010). The considerable growth of Health Policy appears to signal advanced results owing to the availability of funding; yet the capacity to carry out research at the local level has evolved much more slowly, especially in countries with limited economic resources, where research in this area is particularly needed (Adam et al. 2011).

Oncology deserves a mention by virtue of its pattern of communication of high volume and impact, essential for a domain of such relevance at all levels of aggregation. The increase in research related with cancer can be associated with an increase in financing worldwide, and the fact that this category comes into contact with nearly all the domains of the sciences (Eckhouse et al. 2008). It is the second and sometimes the first cause of death in developed countries and in countries with a long life expectancy, where chronic diseases are increasing. Research is still insufficient in some topics, however. For example, surgical oncology research may be hindered by a persistent global cycle of low activity linked to low funding, calling for the introduction of new national and supranational policies for support (Purushotham et al. 2012). It is interesting to see that in Latin America this research field is not one of the most prolific.

Genetics and Immunology and Allergy coincide in having high impact and international collaboration, which probably reflects an element of cause-effect. Work entailing international collaboration has a greater impact in general, because of its multiple "immediate environments," and also because of perceived higher quality or prestige (Lancho Barrantes et al. 2012). Previous authors arrived at findings similar to ours in the case of Immunology and Allergy, their results being based on the Science Citation Index Expanded of Thomson Reuters (Dwivedi 2016).

In Latin America, the behavior of Brazil's scientific output, together with that of Mexico, determines to a great extent the regional pattern of communication and its subject area distribution in Medicine. These two countries have high levels of production that grow at a fast pace, accented by a high incidence of scientific leadership—regardless of whether the contributions are published with or without international collaboration, which should be further analyzed in future studies. In the past 15 years, Brazil's output has secured a better position on the world stage thanks to the efforts that the country has invested, nationwide, in the formation and development of researchers, stimulating both scientific activity and the edition of national and international journals; the former publications play an important role in the infrastructure of scientific communication, both nationally and internationally (Mugnaini et al. 2014).

In the case of Mexico, medical research capacities developed over recent decades have become apparent in overall scientific output, although they have not yet translated into research of high international visibility, in part because they are not published in core journals (Licea de Arenas et al. 2006). Argentina paints a good picture of scientific endeavor that is in accordance with previous studies of the capacity of leading articles in international collaboration (Miguel et al. 2015). Yet the vast differences in the volume and research capabilities of different countries are a matter of concern when constructing valid indicators of international collaboration: the more countries differ in scientific size, the greater the difference in relative terms (Luukkonen et al. 1993). This is the case of Peru and Puerto Rico, with scarce output that nonetheless is of high quality and even excellence, probably signaling high dependency on international collaboration; that is, small countries 
may only be visible in international databases when they sign in collaboration with stronger scientific countries.

At the other extreme we find Cuba, with low impact, low output, and low international collaboration, but better populational health indicators; as demonstrated in previous studies, the people of this country have high levels of health, but low scientific impact (Chinchilla-Rodríguez et al. 2015, 2016b). Cuba's situation is unique, as the scientific community may have been hindered by the longstanding international embargo, scarce publication in the English language, and very limited publication in high impact international journals (Zacca-González et al. 2014b). Venezuela and Jamaica are among the countries with a smaller documented effort in research, even though Jamaica achieves high impact in some of the research fields analyzed. Chile and Colombia remain in intermediate positions as far as research volume, impact and output are concerned, though their rate of growth is accelerated.

Production by country taking into account the number of habitants tells a different story. Even though this variable was not considered in the present analysis, a previous study shows that Cuba and Puerto Rico had a greater volume of publication when the number of documents per one million inhabitants was standardized, followed by Brazil and Chile with approximately five articles per one million inhabitants (Chinchilla-Rodríguez et al. 2015).

The countries of Latin America are particularly productive in the areas of Infectious Diseases and Microbiology and manage to publish papers in the top journals of these specialized domains, but much work has to be done to reach an output of excellence. Infectious Diseases can be seen as a jewel in the crown of Peru. At the same time however, despite a dire regional need, Cardiology and Cardiovascular Medicine is a very weak link in the chain of output in nearly all of Latin America-with the noteworthy exception of Chile, which shows considerable impact, and output in journals of greater prestige.

Latin American research efforts have been deficitary in the categories of Psychiatry and Mental Health, Endocrinology, Diabetes and Metabolism, and Neurology (clinical), even though these domains deal with the main causes for the loss of years of healthy life (Gómez-Dantés et al. 2011). There is high collaboration in the area of Pediatrics, Perinatology and Child Health, and high specialization in Obstetrics and Gynecology at regional level. In these two domains Cuba proves to have superior levels of activity, reflecting its prioritized public health programs; notwithstanding, internationalization, impact and output are very low.

This research paper, and the results it projects, can be seen as a platform of evidence for supporting decision makers in the development of new policies that favor smart specialization and good practices in scholarly communication. The analysis of subject areas is relevant because it substantiates the link between scientific yield in terms of the effort and level of activity undertaken by countries and regions, and brings to light relationships between research capacity, internationalization, the use of outstanding journals, and the generation of high impact research results. Apparently, the most productive and visible relationships respond to the greater burden of diseases-non-transmittable diseases (62.1\%), transmittable (22.3\%) and lesions (15.6\%) (WHO 2008). However, in many cases further studies are needed to untangle these associations at lower levels of aggregation, for instance at the local level and with regard to specific topics.

Through this bibliometric perspective of scientific output, we provide an image of the regional distribution of subject areas in Medicine that could support the design of research agendas when the definition of policies and priorities for research is in progress. International collaboration is replacing other models as the preferred method of building scientific capacity in developing countries (Wagner et al. 2001). Therefore, stimulating 
international collaboration and contributing to the mobilization of human and financial resources so that research in fact fulfills its social role in Health (WHO 2013) could be one key strategy for improving the visibility of scientific output in the countries of Latin America, harnessing specific specialization strengths. Within Latin America, these results can contribute to an understanding of how the system of health research of each country functions, and how output and internationalization could be reinforced in the international scientific context. In short, smart specialization is one means of reserving a relevant position for medical research in a world undergoing rapid transformation, and of supporting health systems in search of universal coverage.

\section{Limitations}

One must bear in mind the limitations of the Activity Index and its relativized version. This indicator reflects a relative position against the standards of reference, but it does not reflect the actual visibility of research in a given field (Hu and Rousseau 2009). The structure of this indicator has been criticized for being a ratio of ratios, a problem that can be traced to introducing the transformation (TSI -1$) /($ TSI +1$)$. If the Activity Index is greater than zero, at least in theory, it is possible to decrease its value, thereby increasing the activity in that field worldwide. While this problem appears to have no real consequences in broad-scale interpretations, it should be regarded with some caution (Rousseau and Yang 2012).

The categorization of the journals might be seen as another limitation of this study, because the classification is done at the journal level, when ideally it would be at the document level. The journals are assigned to one or more categories, and the articles published in them inherit that category, so to speak. Serious problems with this type of study can derive from the overlap of subject categories caused by multiple assignment, or high concentrations of journals produced in certain subject categories (Gómez-Núñez et al. 2014). The fact that the categorization we utilized can be replicated in any scenario makes it better positioned to overcome such limitations.

Another limitation is that in the comparison of the bibliometric indicators, the size of the countries was not taken into account. This important variable must be borne in mind when using the results of this study.

\section{References}

Adam, T., Ahmad, S., Bigdeli, M., Ghaffar, A., \& Røttingen, J. A. (2011). Trends in health policy and systems research over the past decade: Still too little capacity in low-income countries. PLoS ONE, 6(11), e27263. https://doi.org/10.1371/journal.pone.0027263.

Chinchilla-Rodríguez, Z., Zacca-González, G., Vargas-Quesada, B., \& Moya-Anegón, F. (2015). Latinoamerican scientific output in Public Health: Combined analysis of bibliometrics, socioeconomics and health indicators. Scientometrics, 102(1), 609-628. https://doi.org/10.1007/s11192-014-1349-9.

Chinchilla-Rodríguez, Z., Ocaña-Rosa, K., \& Vargas-Quesada, B. (2016a). How to combine research guarantor and collaboration patterns to measure scientific performance of countries in scientific fields: Nanoscience and nanotechnology as a case study. Frontiers in Research Metrics and Analytics, 1(2), 1-15. https://doi.org/10.3389/frma.2016.00002.

Chinchilla-Rodríguez, Z., Zacca-González, G., Vargas-Quesada, B., \& Moya-Anegón, F. (2016b). Benchmarking scientific performance by decomposing leadership of Cuban and Latin American institutions in Public Health. Scientometrics, 106(3), 1239-1264. https://doi.org/10.1007/s11192-015-1831-z. 
Codina-Canet, M. A., Olmeda-Gómez, C., \& Perianes-Rodríguez, A. (2013). Análisis de la producción científica y de la especialización temática de la Universidad Politécnica de Valencia. Scopus (2003-2010). Revista Española de Documentación Científica, 36(3), e019. https://doi.org/10.3989/ redc.2013.3.942.

Dwivedi, S. (2016). Global allergy research during 1994-2013: A scientometric study. Annals of Library and Information Studies, 63, 16-23. http://op.niscair.res.in/index.php/ALIS/article/view/8719. Accessed 13 Feb 2017.

Eckhouse, S., Lewison, G., \& Sullivan, R. (2008). Trends in the global funding and activity of cancer research. Molecular Oncology, 2(1), 20-32. https://doi.org/10.1016/j.molonc.2008.03.007.

Elsevier. (2016). Scopus content coverage guide. https://www.elsevier.com/_data/assets/pdf_file/0007/ 69451/scopus_content_coverage_guide.pdf. Accessed 13 Feb 2017.

European Commission. (2013). Country and regional scientific production profiles. Luxembourg: Publications Office of the European Union. https://ec.europa.eu/research/innovationunion/pdf/scientificproduction-profiles.pdf. Accessed 13 Feb 2017.

Forray, D., \& Goenega, X. (2013). The goals of smart specialisation. JRC Scientific and policy reports, S3 Policy Brief Series. https://doi.org/10.2791/20158.

Fu, J. Y., Zhang, X., Zhao, Y. H., Huang, M. H., \& Chen, D. Z. (2011). Bibliometric analysis of complementary and alternative medicine research over three decades. Scientometrics, 88, 617-626. https:// doi.org/10.1007/s11192-011-0391-0.

Glänzel, W. (2000). Science in Scandinavia: A bibliometric approach. Scientometrics, 48, 121-150. https:// doi.org/10.1023/A:1005640604267.

Glänzel, W., Leta, J., \& Thijs, B. (2006). Science in Brazil. Part 1: A macro-level comparative study. Scientometrics, 67(1), 67-86. https://doi.org/10.1556/Scient.67.2006.1.5.

Gómez-Dantés, H., Castro, M. V., Franco-Marina, F., Bedregal, P., Rodríguez-García, J., Espinoza, A., et al. (2011). La carga de la enfermedad en países de América Latina. Salud Pública de México, 53(2), S72S77. http://www.scielo.org.mx/scielo.php?script=sci_arttext\%26pid=S0036-36342011000800003.

Gómez-Núñez, A. J., Batagelj, V., Vargas-Quesada, B., Moya-Anegón, F., \& Chinchilla-Rodríguez, Z. (2014). Optimizing SCImago Journal \& Country Rank Classification by community detection. Journal of Informetrics, 8(2), 369-383. https://doi.org/10.1016/j.joi.2014.01.011.

Hu, X., \& Rousseau, R. (2009). A comparative study of the difference in research performance in biomedical fields among selected Western and Asian countries. Scientometrics, 81(2), 475-491. https:// doi.org/10.1007/s11192-008-2202-9.

Lancho Barrantes, B. S., Guerrero Bote, V. P., Chinchilla-Rodríguez, Z., \& Moya Anegón, F. (2012). Citation flows in the zones of influence of scientific collaborations. Journal of the Association for Information Science and Tecnology, 63(3), 481-489. https://doi.org/10.1002/asi.21682.

Liang, H. N. (2010). Overview of the health informatics research field: A bibliometric approach. In T. H. Liang (Ed.), E-Health. IFIP advances in information and communication technology (Vol. 35, pp. 37-48). Berlin: Springer. https://doi.org/10.1007/978-3-642-15515-4_5.

Licea de Arenas, J., Arenas, M., Cabello, M., Carmona, V., \& Romero, R. D. (2006). Investigación mexicana significativa en ciencias de la salud 1999-2004. Un análisis bibliométrico. Anales de Documentación, 9, 123-132. http://revistas.um.es/analesdoc/article/view/1371. Accessed 13 Feb 2017.

Luukkonen, T., Tijssen, R., Persson, O., \& Sivertsen, G. (1993). The measurement of international scientific collaboration. Scientometrics, 28(1), 15-36. https://doi.org/10.1007/BF02016282.

Manterola Delgado, C. (2014). Prioridades en Investigación en Salud. International Journal of Medical and Surgical Sciences, 1(4), 347-351. http://www.ijmss.org/wpcontent/uploads/2015/05/art_9_14.pdf. Accessed 13 Feb 2017.

Masic, I. (2013). Medical publication and scientometrics. Journal of Research in Medical Sciences: The Official Journal of Isfahan University of Medical Sciences, 18(6), 516-521. https://www.ncbi.nlm.nih. gov/pmc/articles/PMC3818625/. Accessed 13 Feb 2017.

Miguel, S., González, C., \& Chinchilla-Rodríguez, Z. (2015). Lo local y lo global en la producción científica argentina con visibilidad en Scopus, 2008-2012: Dimensiones nacionales e internacionales de la investigación. Información, cultura y sociedad, 32, 59-78. http://www.scielo.org.ar/scielo.php?script= sci_arttext\%26pid=S1851-17402015000100004. Accessed 13 Feb 2017.

Mugnaini, R., Digiampetri, L. A., \& Mena-Chalco, J. P. (2014). Scientific communication in Brazil (1998-2012): Indexing, growth, flow and dispersion. Transinformação, 26(3), 239-252. https://doi.org/ 10.1590/0103-3786201400030002.

OECD. (2013). Innovation-driven Growth in Regions: The Role of Smart Specialization. Paris: OECD/ OCDE. https://www.oecd.org/innovation/inno/smart-specialisation.pdf. Accessed 13 Feb 2017. 
Organización Mundial de la Salud. (2013). Informe sobre la salud en el mundo 2013: investigaciones para una cobertura sanitaria universal. http://apps.who.int/iris/bitstream/10665/85763/1/9789240691223_ spa.pdf. Accessed 13 Feb 2017.

Parliamentary Office of Science and Technology. (2004). Scientific capacity in developing countries. Postnote, 216. http://researchbriefings.files.parliament.uk/documents/POST-PN-216/POSTPN-216.pdf. Accessed 13 Feb 2017.

Purushotham, A. D., Lewison, G., \& Sullivan, R. (2012). The state of research and development in global cancer surgery. Annals of Surgery, 255(3), 427-432. https://doi.org/10.1097/SLA.0b013e318246591f.

Red Iberoamericana de Indicadores de Ciencia y Tecnologia. (2016). El Estado de la Ciencia 2016. Obtenido de RICYT: http://www.ricyt.org/publicaciones.

Rousseau, R., \& Yang, L. (2012). Reflections on the activity index and related indicators. Journal of Informetrics, 6, 413-421. https://doi.org/10.1016/j.joi.2012.01.004.

Scimago Institutions Rankings. (2017). SIR Methodology. http://www.scimagoir.com/methodology.php. Accessed 14 Feb 2017.

Souza, C., de Filippo, D., \& Sanz Casado, E. (2015). Perfiles de especialización de la producción científica de las universidades de Brasil y España. Desafíos y oportunidades de las Ciencias de la Información y la Documentación en la era digital. Actas del VII Encuentro Ibérico EDICIC 2015. Madrid: Universidad Complutense de Madrid. http://edicic2015.org.es/ucmdocs/actas/art/171-deSouza_ universidades-Br-Es.pdf.. Accessed 13 Feb 2017.

Torres-Salinas, D., Robinson-García, N., Campanario, J., \& Delgado López-Cózar, E. (2013). Coverage, specialization and impact of scientific publishers in the Book Citation Index. Online Information Review, 38(1), 24-42. https://doi.org/10.1108/OIR-10-2012-0169

van Raan, A. (2014). Advances in bibliometric analysis: Research performance assessment and science mapping. In W. Blockmans, L. Engwall, \& D. Weaire (Eds.), Bibliometrics: Use and abuse in the review of research performance (pp. 17-28). London: Portland Press Ltd.

Wagner, C., Brahmakulam, I., Jackson, B., Wong, A., \& Yoda, T. (2001) Science and Technology Collaboration: Building Capacity in Developing Countries? https://www.rand.org/content/dam/rand/pubs/ monograph_reports/2005/MR1357.0.pdf. Accessed 13 Feb 2017.

World Health Organization. (2008). The global burden of disease. 2004. Update. Washington: WHO. http:// www.who.int/healthinfo/global_burden_disease/GBD_report_2004update_full.pdf. Accessed 13 Feb 2017.

World Health Organization. (2013). Research for universal health coverage: World health report 2013. Geneva: World Health Organization. http://apps.who.int/iris/bitstream/10665/85761/2/9789240690837_ eng.pdf?ua=1. Accessed 13 Feb 2017

World Health Organization. (2017). The top 10 causes of death. http://www.who.int/mediacentre/factsheets/ fs310/en/. Accessed 13 Feb 2017.

Zacca-González, G., Chinchilla-Rodríguez, Z., Vargas-Quesada, B., \& de Moya-Anegón, F. (2014a). Bibliometric analysis of regional Latin America's scientific output in Public Health through SCImago Journal \& Country Rank. BMC Public Health, 14(632), 1-11. https://doi.org/10.1186/1471-2458-14632.

Zacca-González, G., Vargas-Quesada, B., Chinchilla-Rodríguez, Z., \& Moya-Anegón, F. (2014b). Producción científica cubana en Medicina y Salud Pública: Scopus 2003-2011. TransInformação, 26(3), 281-293. https://doi.org/10.1590/0103-3786201400030005. 